\title{
Artificial Metalloenzymes for Enantioselective Catalysis Based on the Biotin-Avidin Technology
}

\author{
Jincheng Mao and Thomas R. Ward*
}

\begin{abstract}
Artificial metalloenzymes, based on the incorporation of a biotinylated catalytically active organometallic moiety within streptavidin, offer an attractive alternative to homogeneous, heterogeneous and enzymatic catalysis. In this account, we outline our recent results and implications in the developments of such artificial metalloenzymes for various asymmetric transformations, including hydrogenation, transfer hydrogenation, allylic alkylation and sulfoxidation.
\end{abstract}

Keywords: Artificial metalloenzymes · Asymmetric catalysis · Biotin-(strept)avidin technology · Enantioselectivity

\section{Introduction}

In order to meet the ever-increasing demand for enantiopure compounds, heterogeneous-, homogeneous- and enzymatic catalysis have evolved independently in the past years. ${ }^{[1,2]}$ Although all three approaches have yielded industrially viable processes, the latter two are the most widely used and can be regarded as complementary in many respects. ${ }^{[3]}$ Despite the progress in structural, computational and mechanistic studies however, there exists to date no universal recipe for the optimization of a catalytic process. Thus, a trial-and-error approach remains predominant in catalyst discovery and optimization.
${ }^{\star}$ Correspondence: Prof. Dr. T. R. Ward

Department of Chemistry

University of Basel

Spitalstrasse 51

$\mathrm{CH}-4056$ Basel

Tel: +41612671004

Fax: +41612671005

E-mail: thomas.ward@unibas.ch
With the aim of complementing the well-established fields of homogeneous and enzymatic catalysis, organocatalysis and artificial metalloenzymes have witnessed a recent revival. ${ }^{[4,5]}$ Artificial metalloenzymes result from the combination of an active but unselective organometallic moiety with a macromolecular host (protein or DNA) as shown in Fig. 1.

Both Kaiser and Whitesides suggested the possibility of creating artificial metalloenzymes in the late 1970s. ${ }^{[6,7]}$ However, at that time there was a widespread belief that proteins and organometallic catalysts are incompatible with each other. This severely hampered research in this area at the interface between homogeneous and enzymatic catalysis. ${ }^{[8]}$ Since 2000 however, there has been increasing interest in the field of artificial metalloenzymes for enantioselective catalysis. ${ }^{[9-13]}$

For the localization of an organometallic moiety within a macromolecular host, three anchoring strategies can be envisaged: covalent, dative or supramolecular. ${ }^{[5]}$ Using such approaches, enantioselective artificial metalloenzymes have been created for hydrolysis, [12] hydrogenation, , ${ }^{[14-17]}$ transfer hydrogenation, ${ }^{[18]}$ allylic alkylation, [19] sulfoxidation, ${ }^{[20-24]}$ epoxidation, ${ }^{[25,26]}$ dihydroxylation, ${ }^{[27]}$ Diels-Alder, ${ }^{[28,29]}$ trans-amination, ${ }^{[30]}$ Michael addition ${ }^{[31]}$ and fluorination. ${ }^{[32]}$ Comparatively, supramolecular anchoring appears as the most appealing, since it allows separate variation of both biological and chemical components, followed by straightforward combination of the organometallic moiety and the macromolecular host. In addition, no chemical

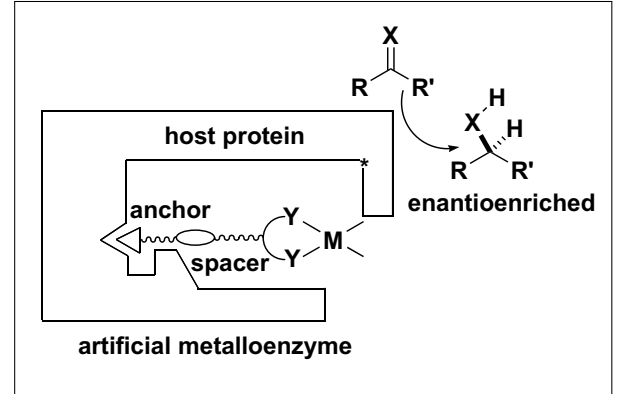

Fig. 1. Anchoring a catalytically active but unselective organometallic catalyst within a host protein affords artificial metalloenzymes for enantioselective catalysis. Chemical optimization can be achieved either by varying the spacer (oval) or the chelating ligand. Site-directed or random mutagenesis at a position close to the metal moiety $\left(^{*}\right)$ can be used for the genetic optimisation.

modification step is required after the incorporation of the catalyst precursor, thus ensuring the integrity of the organometallic species. In recent years, we have been exploiting the biotin-avidin technology for the creation of artificial metalloenzymes for enantioselective catalysis. Herein we summarize the challenges and our progress in this area.

\section{Results and Discussion}

\section{The Biotin-Avidin Technology}

The biotin-avidin technology, often referred to as molecular velcro, relies on the very high affinity of biotin for either avidin 
or streptavidin - (strept)avidin hereafter.[33] The versatility of this technology can be traced back to the following features:

i) The nearly irreversible interaction between biotin and (strept)avidin relies solely on hydrogen bonds and hydrophobic interactions and thus can reliably take place in a variety of environments (cell, blood, surfaces etc.) under mild conditions (Fig. 2).

ii) A straightforward amide bond-forming reaction allows a biotin moiety to be appended to nearly any probe. This derivatization of the valeric acid side chain of biotin does not significantly affect the high affinity of the biotin-avidin couple.[34]

iii) (Strept)avidin possesses a homotetrameric $\beta$-barrel structure with four equivalent biotin-binding sites. This allows different moieties to be brought into close proximity via the biotin-avidin technology.

iv) (Strept)avidin is a very robust protein scaffold which can be easily handled by inexperienced chemists without the risk of losing biotin-binding activity.

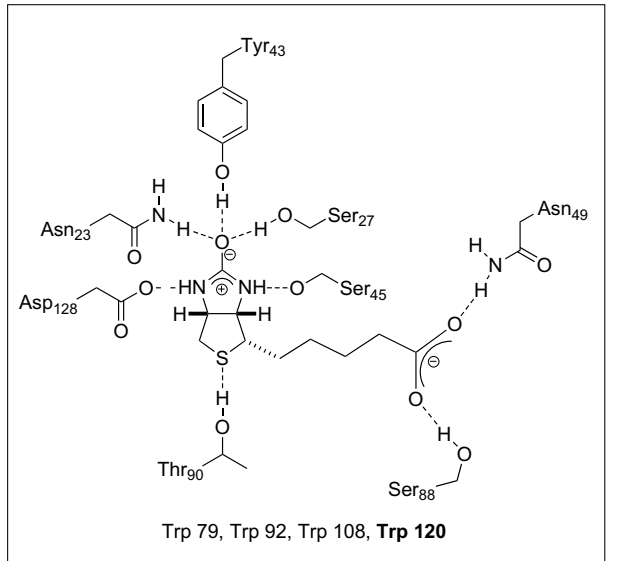

Fig. 2. Interactions responsible for the biotinstreptavidin affinity $\left(K_{a}\right.$ ca. $\left.10^{14} \mathrm{M}^{-1}\right)$. In addition to the hydrogen-bonding network, the biotinbinding site is lined with four tryptophane residues, one of which, $\operatorname{Trp} 120$, is provided by the adjacent streptavidin monomer.

In the past four decades, this versatile tool has found numerous applications in affinity chromatography, signal amplification, drug delivery, immunoassays, immobilization etc. ${ }^{[35]}$

Inspired by the pioneering work of the Whitesides group, ${ }^{[7,17]}$ we reasoned that we could exploit the biotin-avidin technology for the creation and optimization of artificial metalloenzymes. Introduction of a biotin anchor on a chelating ligand ensures the localization of an organometallic moiety within a chiral environment provided by (strept) avidin. We endeavored to use modern tools of genetic and chemical optimization to fine-tune the second coordination sphere of the resulting artificial metalloenzymes. The main stages include i) mutation and overexpression of the (strept)avidin isoform in a suitable host, ii) isolation, purification and quantification of the activity of the mutated (strept)avidin, iii) synthesis of the biotinylated catalyst precursor and incorporation within (strept)avidin, iv) catalysis, and v) product isolation and analysis.

One of the most attractive features of this approach is the diversity generated by combining both chemical and genetic optimization strategies. ${ }^{[36]}$ Following this approach, we have been able to develop artificial metalloenzymes for the hydrogenation, the allylic alkylation and the transfer hydrogenation reaction.

\section{The Chemical Optimization Dimension}

In the spirit of homogeneous catalyst optimization, variation of the first coordination sphere provided by a chelating ligand often has a significant impact on the performance of the resulting catalyst. Inspired by some of the best homogeneous catalysts, a series of aminodiphosphines and aminosulfonamides were synthesized and coupled with the biotin-anchor. We reasoned that introduction of a spacer between the biotin and the chelating ligand would project a different chiral environment for each biotinspacer-ligand combination, thus offering a straightforward optimization strategy. The most versatile ligands and spacers are shown in Fig. 3.

\section{The Genetic Optimization Dimension}

Considering the ease of recombinant protein production in various hosts, we set out to produce streptavidin (Sav hereafter) in Escherichia coli and avidin (Avi hereafter) in Pichia pastoris. ${ }^{[37,38]}$ Although in our hands both proteins could be overexpressed to high levels $\left(230 \mathrm{mg} \cdot \mathrm{l}^{-1}\right.$ cell culture and
$330 \mathrm{mg} \cdot \mathrm{l}^{-1}$ cell culture respectively) streptavidin was eventually preferred over avidin for the following reasons:

i) In contrast to streptavidin, avidin is glycosylated. This is a source of inhomogeneity and thus may cause reproducibility concerns. In addition, the inhomogeneity renders crystallization more challenging.

ii) Each avidin monomer possesses a single intramolecular disulfide bridge. As a consequence, the protein cannot be denatured and renatured, which is a limitation for purification purposes.

iii) $E$. coli is a well behaved and a very easy to handle organism for the overexpression of recombinant proteins. However, it should be emphasized that $P$. pastoris secretes the recombinant proteins in the culture medium, which could be a major asset for future directed evolution studies.

In light of the above reasons and considering that our initial success was obtained with streptavidin rather than avidin, ${ }^{[14]}$ we rapidly focused on streptavidin and mutants thereof as host for artificial metalloenzymes.

Docking studies performed with either $[\mathrm{Rh}(\mathrm{COD})(\text { Biot-1 })]^{+}$or $\left[\mathrm{Ru}\left(\eta^{6}\right.\right.$-arene $)$ $\mathrm{H}\left(\right.$ Biot-III $\left.\left.{ }^{p}-2\right)\right]$ within WT-Sav revealed that the potential energy surface describing the localization of the metal within the protein environment was flat and the metal adopted different positions within a very small energy window. ${ }^{39,40]}$ Analysis of the $\mathrm{C}_{\alpha}-\mathrm{M}$ distances revealed that the asymmetric carbon $\left(\mathrm{C}_{\alpha}\right)$ of residue $\mathrm{S} 112 \mathrm{Sav}$ lay systematically closest to the metal center. Based on these in silico studies, we set out to produce all twenty Sav isoforms resulting from saturation mutagenesis at position S112X Sav. ${ }^{[41]}$ Except for S112P Sav

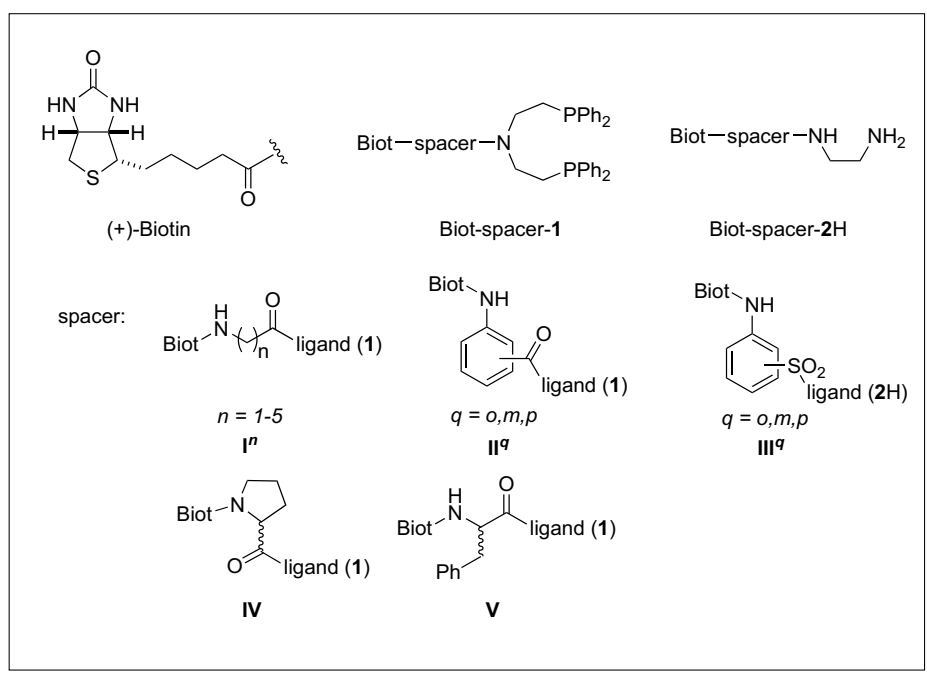

Fig. 3. Chemical diversity generated by combining different biotinylated spacers and ligands. After addition of a suitable metal source, the resulting biotinylated organometallic catalyst precursors are combined with (strept) avidin to afford artificial metalloenzymes. 
(which afforded low levels of pure protein), all mutants could be produced in high yield and purified from 10 liter $E$ coli fermentations.

\section{Artificial Hydrogenases}

Having synthesized a library of biotinylated diphosphine ligands, these were reacted with $[\mathrm{Rh}(\mathrm{COD})]^{+}$and combined with a Sav isoform. The resulting artificial metalloenzymes were screened for the reduction of $\mathrm{N}$-acetamidodehydroalanine and $\mathrm{N}$ acetamidodehydrophenylalanine to afford $N$-acetamidodehydroalanine $\quad(N$-AcAla) and $\mathrm{N}$-acetamidophenylalanine $(\mathrm{N}-\mathrm{AcPh})$ respectively (Scheme 1). Overall, twentytwo ligands were screened in the presence of the twenty Sav isoforms and WT Avi. Noteworthy results are collected in Table 1. ${ }^{[14,41-45]}$ Based on these data, the following trends can be identified:

i) Both $(R)$ - and $(S)$-enantiomers of the product can be obtained in good enantioselectivities (>90\% ee, Table 1. entries 1-6)

ii) Chemical diversity (e.g. variation of the spacer) is a more versatile means for optimization that genetic diversity. This latter can be regarded as a fine tuning step.

iii) Introduction of conformationally constrained spacers (e.g. proline IV) confers significant organic solvent tolerance to the systems. Both biphasic and dmso/water mixtures yield good conversions and selectivities (Table 1, entries 3-5). ${ }^{[45]}$

iv) The artificial hydrogenases follow Michaelis-Menten kinetics. Introduction of the catalyst within streptavidin contributes to improve both the activity (e.g. phenomenon of protein-accelerated catalysis, compare $[\mathrm{Rh}(\mathrm{COD})(\operatorname{Biot}-\mathbf{1})]^{+}$, $k_{\text {cat }} 3.06 \mathrm{~min}^{-1}, K_{M} 7.38 \mathrm{mM}$, with $[\mathrm{Rh}(\mathrm{COD})(\text { Biot}-(R)-\mathbf{I V}-\mathbf{1})]^{+} \subset \mathrm{WT}$ Sav, $\left.k_{\text {cat }} 12.30 \mathrm{~min}^{-1}, K_{M} 4.36 \mathrm{mM}\right)$ and the selectivity. ${ }^{[42]}$

v) Although most ligand-protein combinations afford comparable levels of conversion and enantioselectivity for both substratres, certain combinations yield substrate specific artificial hydrogenases (Table 1 , entry 6).

Having demonstrated the potential of artificial metalloenzymes for the reduction of $\mathrm{N}$-protected dehydroaminoacids, we turned our attention towards organometallic-catalyzed reactions where the enantiodiscrimination step occurs without coordination of one of the reactants to the metal center. We anticipated that incorporation of the metal complex within a protein environment may steer the enantioselection without requiring transient coordination to the metal. In this context, we selected palladium-catalyzed asymmetric allylic alkylation, rutheniumcatalyzed transfer hydrogenation and the vanadyl-catalyzed sulfoxidation reaction. Indeed, these reactions are believed to pro-

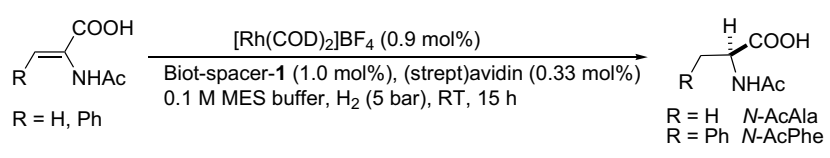

Scheme 1. Substrates and operating conditions used for the hydrogenation reaction catalyzed by artificial metalloenzymes based on the biotin-avidin technology

Table 1. Selected results obtained for the hydrogenation reaction

\begin{tabular}{cllclcl} 
Entry & Ligand & Protein & $\begin{array}{l}\text { ee [\%] } \\
\text { N-AcAla }\end{array}$ & $\begin{array}{l}\text { Conv. [\%] } \\
\text { N-AcAla }\end{array}$ & $\begin{array}{l}\text { ee [\%] } \\
\text { N-AcPhe }\end{array}$ & $\begin{array}{l}\text { Conv. [\%] } \\
\text { N-AcPhe }\end{array}$ \\
\hline 1 & Biot-1 & WT Sav & 94 & quant. & 93 & 84 \\
2 & Biot-1 & S112A & 93 & quant. & 94 & 94 \\
$3^{\text {c }}$ & Biot- $(R)-I V-1$ & S112W & -94 & 98 & -94 & 86 \\
$4^{\text {d }}$ & Biot- $(R)-I V-1$ & WT Sav & -87 & quant. & -91 & quant. \\
$5^{\text {e }}$ & Biot- $(R)-I V-1$ & WT Sav & -87 & quant. & -86 & 94 \\
6 & Biot- $(R)-I V-1$ & S112E & -79 & quant. & -55 & 16
\end{tabular}

apositive ee values in favour of the $(R)$-enantiomer, negative ee values in favour of the $(S)$ enantiomer; ${ }^{\mathrm{b}}$ quant. = Quantitative. ${ }^{\mathrm{c} B i p h a s i c ;}{ }^{\mathrm{d}} 27 \%$ DMSO; ${ }^{\mathrm{e}} 45 \% \mathrm{DMSO}$.

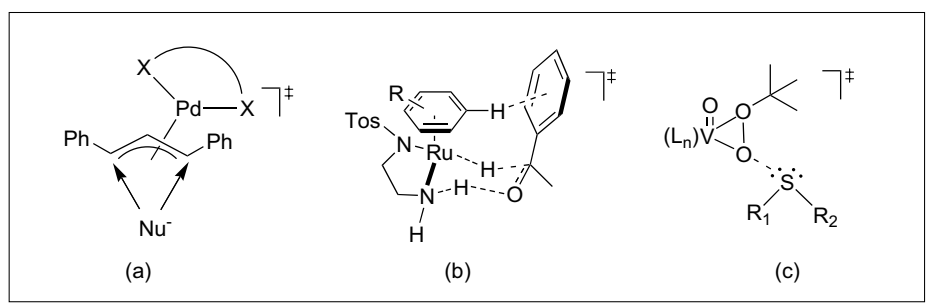

Fig. 4. Postulated transition states of homogeneous enantioselective reactions which proceed without coordination of one of the substrates to the metal center: allylic alkylation (a), transfer hydrogenation (b) and sulfoxidation (c)

ceed without prior coordination of the soft nucleophile, the prochiral ketone or the prochiral sulfide respectively (Fig. 4).

\section{Artificial Allylic Alkylases}

In the field of $\mathrm{C}-\mathrm{C}$ bond forming reactions, palladium occupies a priviledged position. ${ }^{[46]}$ In this context, asymmetric allylic alkylation attracted our interest due to its unique outersphere attack of the malonate on the $\eta^{3}$-coordinated 1,3-diphenylallyl moiety.[47]

Following the above-described chemogenetic optimization procedure, we screened twenty-one biotinylated ligands in conjunction with twenty two (strept)avidin isoforms for the allylic aklylation of 1,3-diphenylallyl acetate. Addition of didodecyldimethylammonium bromide (DMB) allowed a significant improvement of the yield of alkylation product - over the hydrolysis product, 1,3-diphenylallylalcohol, formed predominantly in the absence of DMB - (Scheme 2). This screening revealed the following trends: ${ }^{[19]}$

i) The nature of the spacer plays a critical role in conferring activity to the artificial alkylase. In most cases and despite the addition of DMB, the hydrolysis product was formed predominantly. The best spacers are conformationally constrained: either proline IV or $o$-aminobenzoate II $^{o}$ (Table 2, entries 1-3).

ii) Despite the presence of chaotropic agents (surfactant and basic $\mathrm{pH}$ ), the artificial metalloenzymes behave remarkably well. While the high $\mathrm{pH}$ is required for the reaction to proceed, the reaction carried out in the absence of DMB leads to a significant erosion of the conversion, with only a modest increase in selectivity (Table 2, entries 3,4 ).

iii) As previously observed for the hydrogenation reaction, conformationally constrained ligands confer improved organic solvent tolerance. Reactions with $\left[\mathrm{Pd}\left(\eta^{3} \text {-allyl }\right)\left(\text { Biot-II }{ }^{\circ}-\mathbf{1}\right)\right]^{+} \subset$ S112A Sav can be performed in $45 \%$ dmso without addition of DMB (Table 2 , entry 5). ${ }^{[48]}$

iv) Again here, the versatility of the chemical optimization allowed the rapid iden- 
tification of an active biotinylated ligand. The genetic optimization can be regarded as a fine-tuning step: whereas most streptavidin isoforms yielded $(R)$-alkylation products in conjunction with $\left[\operatorname{Pd}\left(\eta^{3} \text {-allyl }\right)\left(\operatorname{Biot}-\mathbf{I I}^{o}-\mathbf{1}\right)\right]^{+}$, S112Q clearly stands out as it affords the $(S)$-alkylation product (Table 2, entry 6$)$.

\section{Artificial Transfer Hydrogenase}

The asymmetric transfer hydrogenation of ketones is an effective way to prepare enantiopure alcohols. ${ }^{[49]}$ We were attracted to this reaction as we anticipated that one could exploit the reversibility of the reaction to perform either the enantioselective reduction or the kinetic resolution of racemic alcohols via oxidation. ${ }^{[50]}$ This behaviour is reminiscent of alcohol dehydrogenases which can operate either as oxidases or reductases. ${ }^{[2]}$

Incorporation of a biotinylated $\mathrm{d}^{6}$-piano-stool complex bearing a biotinylated aminosulfonamide ligand into streptavidin afforded artificial transfer hydrogenases for the reduction of acetophenone derivatives. A buffered solution ( $\mathrm{pH}$ 6.25) containing sodium formate as a hydrogen source proved best in terms of conversion and selectivity. Unexpectedly, the performance of the artificial metalloenzyme was improved by raising the temperature to $55^{\circ} \mathrm{C} .[18,39,51]$ A combined chemo-genetic procedure combining twenty-one pianostool complexes with the twenty S112X Sav isoforms allowed the activity and the selectivity of these hybrid catalysts for the reduction of prochiral ketones to be optimized (Scheme 3). The following trends were identified:[52]

i) Only catalysts bearing the para-substituted spacer biot-III ${ }^{p}-\mathbf{2}$ afforded any significant level of conversion.

ii) Ruthenium-based catalysts $\left[\mathrm{Ru}\left(\eta^{6}\right.\right.$ arene)H(Biot-III $\left.\left.{ }^{p}-\mathbf{2}\right)\right] \quad$ outperformed either rhodium or iridium based systems $\left[\mathrm{M}\left(\eta^{5}-\mathrm{C}_{5} \mathrm{Me}_{5}\right) \mathrm{H}\left(\right.\right.$ Biot-III $\left.\left.^{p}-\mathbf{2}\right)\right]$.

iii) Under otherwise identical conditions, the $p$-cymene $\left[\mathrm{Ru}\left(\eta^{6}-p\right.\right.$-cymene $)$ $\mathrm{H}\left(\right.$ Biot-III $\left.\left.^{p}-\mathbf{2}\right)\right]$ and the benzene $\left[\mathrm{Ru}\left(\eta^{6}-p\right.\right.$-benzene $\left.) \mathrm{H}\left(\mathrm{Biot}-\mathbf{I I I}{ }^{p}-\mathbf{2}\right)\right]$ complexes afforded opposite enantiomers (Table 3, entries 1, 2).

iv) Various acetophenone derivatives could be reduced with good enantioselectivites up to $97 \%$ ee for $(R)$-products and $92 \%$ ee for $(S)$-products (Table 3, entries 3,6$)$.

v) In contrast, the selectivities obtained for the reduction of dialkylketones remained modest (Table 3, entries 4, 5).

In the context of transfer-hydrogenation, dialkylketones are challenging substrates as the major contribution to the enantiodiscrimination event is believed to be $\mathrm{C}-\mathrm{H} \cdots \cdots \cdot \pi$ interactions between the $\eta^{6}$ -

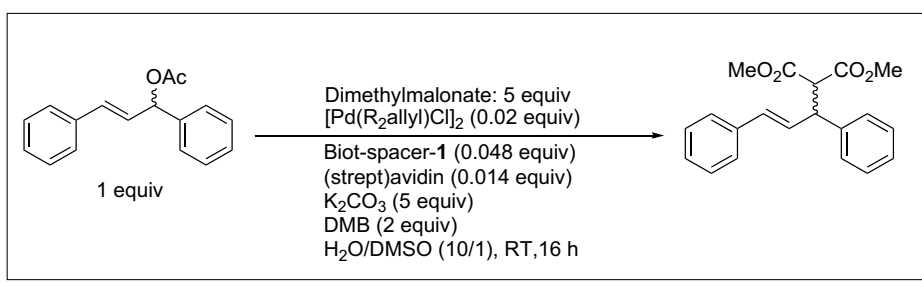

Scheme 2. Operating conditions used for the asymmetric allylic alkylation catalyzed by artificial metalloenzymes based on the biotin-avidin technology.

Table 2. Selected results obtained for the asymmetric allylic alkylation

\begin{tabular}{|c|c|c|c|c|}
\hline Entry & Ligand & Protein & ee $[\%]^{a}$ & Conv. [\%] \\
\hline 1 & Biot- $(R)-\mathbf{I V - 1}$ & S112G V47G & -82 & 92 \\
\hline 2 & Biot-II0-1 & S112G & 88 & 95 \\
\hline 3 & Biot-IIO-1 & S112A & 90 & 95 \\
\hline $4^{b}$ & Biot-IIO-1 & S112A & 93 & 20 \\
\hline $5^{\mathrm{b}, \mathrm{c}}$ & Biot-IIO-1 & S112A & 95 & 90 \\
\hline 6 & Biot-II-1 & S112Q & -31 & 96 \\
\hline
\end{tabular}

apositive ee values in favour of the $(R)$-enantiomer, negative ee values in favour of the $(S)$ enantiomer. ${ }^{b}$ No DMB was added. ${ }^{c}$ The reaction was performed in 45\% DMSO.

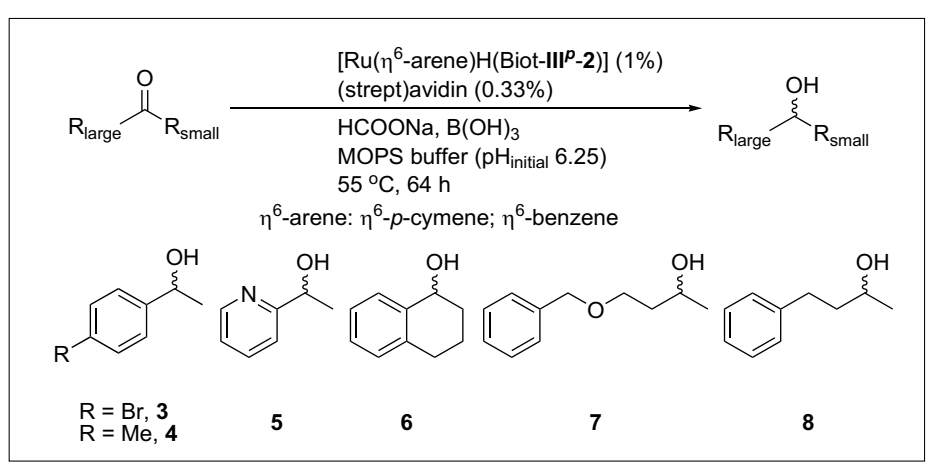

Scheme 3. Substrates and operating conditions used for the transfer hydrogenation catalyzed by artificial metalloenzymes based on the biotinavidin technology.

Table 3. Selected results obtained for the transfer hydrogenation using $\left[\mathrm{Ru}\left(\mathrm{h}^{6}-\mathrm{p}\right.\right.$-benzene)Cl(BiotIIIP-2)]

$\begin{array}{llllll}\text { Entry } & \mathrm{h}^{6} \text {-Arene } & \text { Protein } & \text { Product } & \text { ee [\%] } & \text { Conv. [\%] } \\ 1 & \text { p-cymene } & \mathrm{S} 112 \mathrm{~A} & \mathbf{4} & 91 & 98 \\ 2 & \text { benzene } & \mathrm{S} 112 \mathrm{~T} & \mathbf{3} & -55 & 90 \\ 3 & p \text {-cymene } & \mathrm{S} 112 \mathrm{Y} & \mathbf{6} & 97 & 79 \\ 4 & \text { p-cymene } & \mathrm{S} 112 \mathrm{~A} & \mathbf{8} & 48 & 98 \\ 5 & \text { p-cymene } & \mathrm{S} 112 \mathrm{~A} & \mathbf{7} & 69 & 97 \\ 6 & \text { p-cymene } & \mathrm{S} 112 \mathrm{~A} \mathrm{~K} 121 \mathrm{~N} & \mathbf{5} & -92 & \text { quant. }^{\mathrm{b}} \\ 7 & \text { p-cymene } & \mathrm{S} 112 \mathrm{~A} \mathrm{~K} 121 \mathrm{~T} & \mathbf{7} & 90 & \text { quant. }^{\mathrm{b}} \\ 8 & \text { p-cymene } & \mathrm{S} 112 \mathrm{~A} \mathrm{~K} 121 \mathrm{~T} & \mathbf{8} & 88 & 99\end{array}$

apositive and negative ee values correspond to the $R$ and $S$ enantiomers, respectively; ${ }^{\mathrm{b}}$ Quantitative

bound arene and the phenyl moiety on the prochiral substrate (Fig. 4). ${ }^{53-55]}$ We anticipated that the introduction of additional sites of mutation in the proximity of the piano-stool moiety may allow this challenge to be addressed. For this purpose, we invested considerable effort into crystallizing the most promising $(R)$ - and $(S)$-selective artificial metalloenzymes: $\left[\mathrm{Ru}\left(\eta^{6}-p\right.\right.$-benzene $)$ $\left.\mathrm{Cl}\left(\mathrm{Biot}_{-} \mathbf{I I I}{ }^{p}-2\right)\right] \subset \mathrm{S} 112 \mathrm{~K}$ Sav and $\left[\mathrm{Ru}\left(\eta^{6}{ }_{-}\right.\right.$ $p$-cymene $) \mathrm{Cl}\left(\right.$ Biot-III $\left.\left.^{p}-2\right)\right] \subset \mathrm{S} 112 \mathrm{~A}$ Sav. We were fortunate to succeed in crystallizing the former and its structure is depicted in Fig. 5. ${ }^{[51]}$ Based on this structure, we per- 
formed an additional round of mutations, concentrating on the close-lying K121 and L124 residues and using WT Sav, S112K and $\mathrm{S} 112 \mathrm{~A}$ as background, thus affording a total $120 \mathrm{Sav}$ isoforms. In order to speed up the optimization process, a straightforward Sav immobilization procedure was implemented.[51] For this purpose, commercially available biotinylated sepharose was added to the supernatant of the $E$. coli lysed cell cultures. After centrifugation, the immobilized Sav mutants, which on average possessed three remaining biotinbinding sites, were treated with an excess of $\left[\mathrm{Ru}\left(\eta^{6}\right.\right.$-arene $\left.) \mathrm{Cl}\left(\mathrm{Biot}_{-} \mathbf{I I I}{ }^{p}-\mathbf{2}\right)\right]$, washed and tested in the presence of Sav. This second optimization round allowed to identify artificial transfer hydrogenases which displayed much improved selectivities towards dialkylketones (Table 3 , entries 7 , 8).

Having developed an efficient artificial transfer hydrogenase, we attempted to apply the same methodology to the reverse reaction: the kinetic resolution of racemic alcohols. To our disappointment, we were forced to use strong oxidizing agents (e.g. $t$ - $\mathrm{BuOOH}$ rather than acetone, in the spirit of an Oppenauer-type mechanism) to drive the reaction to completion. ${ }^{[56]}$ We speculate that, in the presence of water, the ruthenium is unable to abstract the $\beta$-hydrogen on the prochiral alcohol.

Despite the excitement generated by the X-ray structure, the localization of the biotinylated metal complex within the protein environment was a source of disappointment. Indeed, we anticipated that the active catalyst would be located inside the biotin-binding pocket of Sav rather than on the surface of the protein. To overcome this problem we tested whether the polar residues present within the biotin-binding pocket itself (Fig. 2) may be capable of binding a polar coordination complex. With this goal in mind, we tested the catalytic potential of vanadyl as a catalyst. ${ }^{[57]}$

\section{Enantioselective Sulfoxidation Based on Vanadyl-loaded Streptavidin}

Addition of vanadyl sulfate to Sav affords an artificial oxidase for the sulfoxidation of prochiral sulfides. The system is most efficient at low $\mathrm{pH}(2.2)$ and organic peroxides are required for efficient catalysis (Scheme 4). From the screening, the following trends emerge:[21]

i) A variety of prochiral sulfides are oxidized to the corresponding sulfoxides with no overoxidation.

ii) At room temperature and relying on 0.02 equivalents vanadium, the conversions are complete in most cases and the $(R)$-selectivities often exceed $90 \%$ (Table 4, entries 1-5).

iii) Since there is no ligand, the system cannot be optimized chemically.

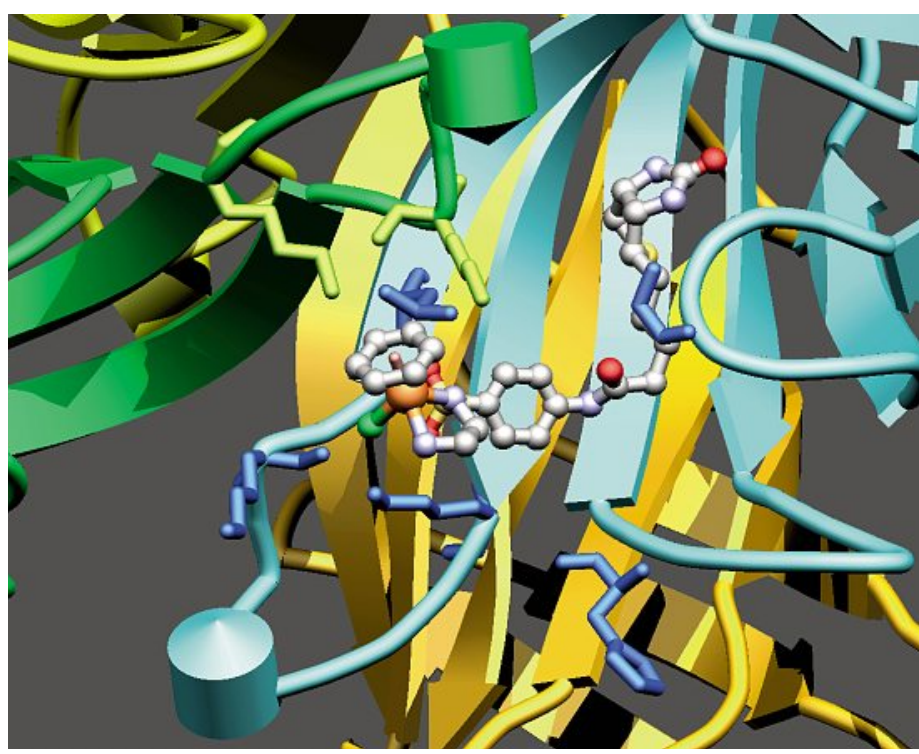

Fig. 5. Close-up view of the X-ray crystal structure of $\left[R u\left(\eta^{6}-p\right.\right.$-benzene) $\mathrm{Cl}\left(\right.$ Biot-III $\left.\left.\mathrm{P}_{-}\right)\right] \subset \mathrm{S} 112 \mathrm{~K}$ Sav. The ruthenium position is partially occupied (20\%). The absolute configuration at $\mathrm{Ru}$ is $(\mathrm{S})$.

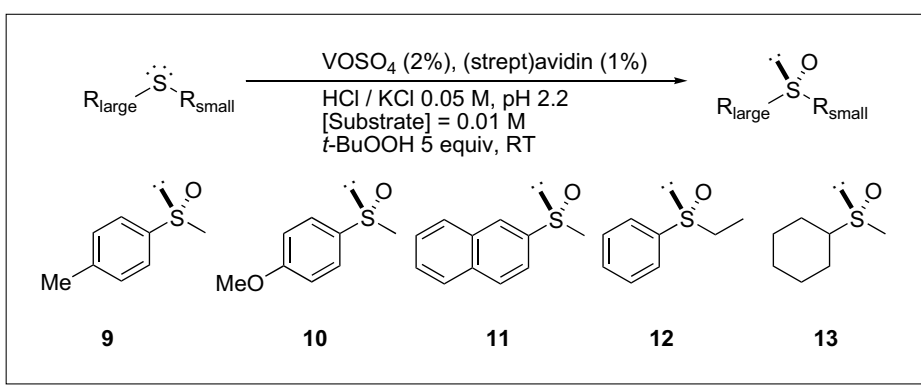

Scheme 4. Substrates and operating conditions used for sulfoxidation catalyzed by artificial metalloenzymes based on vanadyl-loaded streptavidin.

Table 4. Selected results obtained for the sulfoxidation reaction

\begin{tabular}{|c|c|c|c|c|c|}
\hline Entry & protein & Vanadium source & Product & ee $[\%]^{a}$ & Conv. [\%] \\
\hline 1 & WT Sav & $\mathrm{VOSO}_{4}$ & 9 & 87 & 96 \\
\hline 2 & WT Sav & $\mathrm{VOSO}_{4}$ & 10 & 90 & quant. ${ }^{b}$ \\
\hline 3 & WT Sav & $\mathrm{VOSO}_{4}$ & 11 & 93 & 53 \\
\hline 4 & WT Sav & $\mathrm{VOSO}_{4}$ & 12 & 90 & 96 \\
\hline 5 & WT Sav & $\mathrm{VOSO}_{4}$ & 13 & 86 & 61 \\
\hline 6 & WT Sav + biotin & $\mathrm{VOSO}_{4}$ & 10 & 0 & 96 \\
\hline 7 & D128A & $\mathrm{VOSO}_{4}$ & 10 & 0 & 97 \\
\hline 8 & Aviloopc & $\mathrm{VOSO}_{4}$ & 13 & 90 & 54 \\
\hline
\end{tabular}

iv) In the presence of biotin-loaded Sav, the sulfoxidation with $\mathrm{VOSO}_{4}$ affords racemic product, suggesting that vanadium cannot compete for binding with biotin (Table 4, entry 6).

v) It is widely recognized that residue D128 Sav is most important in biotinbinding (see Fig. 2).[58] The mutant D128A Sav affords racemic sulfoxide, thus suggesting that the vanadyl moiety is located within the biotin-binding site (Table 4, entry 7).

vi) Replacement of the L3,4-loop of Sav by the corresponding L3,4-loop of Avi affords a chimaeric protein (Aviloop) ${ }^{[59]}$ with improved properties for the sulfoxidation of dialkylsulfides (Table 4, entries 8). 


\section{Conclusions and Outlook}

As summarized in this review, artificial metalloenzymes based on the biotin-avidin technology have developed into a versatile approach to enantioselective catalysis. In many cases, selectivities exceeding $92 \%$ ee could be obtained, relying on a chemogenetic optimization strategy. Such hybrid catalysts display features which are reminiscent of both homogeneous and enzymatic catalysis. Although the reactions implemented so far are limited to model systems, we believe that these catalysts will reveal their full potential for transformations for which there exists to date no good homogeneous catalyst. In this context, our current efforts are directed towards the hydroxylation of alkanes (where overoxidation is difficult to prevent with homogeneous systems) as well as highly sequence-specific DNA hydrolysis.

\section{Acknowledgements}

This work was funded by the Swiss National Science Foundation (Grants FN 200021-105192 and 200020-113348), the Roche Foundation as well as the FP6 Marie Curie Research Training network (MRTN-CT-2003-505020) and the Canton of Neuchâtel. We thank Umicore Precious Metals Chemistry for a loan of ruthenium. We thank C. R. Cantor for the streptavidin gene.

Received: October 31, 2008

[1] 'Comprehensive Asymmetric Catalysis', Eds. E. N. Jacobsen, A. Pfaltz, H Yamamoto, Springer, Berlin, 1999.

[2] K. Faber, 'Biotransformations in Organic Chemistry', 5th ed., Springer, Berlin, 2004.

[3] M. Breuer, K. Ditrich, T. Habicher, B. Hauer, M. Kesseler, R. Stürmer, T. Zelinski, Angew. Chem., Int. Ed. 2004, 43, 788.

[4] R. Berkessel, H. Gröger, 'Asymmetric Organocatalysis: From Biomimetic Concepts to Applications in Asymmetric Synthesis', Wiley-VCH, Weinheim, 2005.

[5] C. Letondor, T. R. Ward, ChemBioChem 2006, 7,1845 .

[6] E. T. Kaiser, D. S. Lawrence, Science 1984, 226, 505

[7] M. E. Wilson, G. M. Whitesides, J. Am. Chem. Soc. 1978, 100, 306

[8] O. Pàmies, J.-E. Bäckvall, Chem. Rev. 2003, 103, 3247.

[9] T. Ueno, T. Koshiyama, S. Abe, N. Yokoi, M. Ohashi, H. Nakajima, Y. Watanabe, $J$. Organomet. Chem. 2007, 692, 142.

[10] Y. Lu, Angew. Chem., Int. Ed. 2006, 45, 5588.

[11] G. Roelfes, Mol. Biosyst. 2007, 3, 126.

[12] D. Qi, C.-M. Tann, D. Haring, M. D. Distefano, Chem. Rev. 2001, 101, 3081.

[13] C. M. Thomas, T. R. Ward, Chem. Soc. Rev. 2005, 34, 337.

[14] J. Collot, J. Gradinaru, N. Humbert, M. Skander, A. Zocchi, T. R. Ward, J. Am. Chem. Soc. 2003, 125, 9030.

[15] M. T. Reetz, J. J.-P. Peyeralans, A. Maichele, Y. Fu, M. Maywald, Chem. Commun. 2006, 4318.
[16] H. Yamaguchi, T. Hirano, H. Kiminami, D. Taura, A. Harada, Org. Biomol. Chem. 2006, 4, 3571 .

[17] C.-C. Lin, C.-W. Lin, A. S. C. Chan, Tetrahedron Asymmetry 1999, 10, 1887.

[18] C. Letondor, N. Humbert, T. R. Ward, Proc. Natl. Acad. Sci. U. S. A. 2005, 102, 4683.

[19] J. Pierron, C. Malan, M. Creus, J. Gradinaru, I. Hafner, A. Ivanova, A. Sardo, T. R. Ward, Angew. Chem., Int. Ed. 2008, 47, 701 .

[20] F. van de Velde, L. Könemann, F. v. Rantwijk, R. A. Sheldon, Chem. Commun. 1998, 1891.

[21] A. Pordea, M. Creus, J. Panek, C. Duboc, M. Novic, D. Mathis, T. R. Ward, J. Am. Chem. Soc. 2008, 130, 8085.

[22] A. Mahammed, Z. Gross, J. Am. Chem. Soc. 2005, 127, 2883.

[23] M. Ohashi, T. Koshiyama, T. Ueno, M. Yanase, H. Fujii, Y. Watanabe, Angew. Chem., Int. Ed. 2003, 42, 1005.

[24] J. R. Carey, S. K. Ma, T. D. Pfister, D. K. Garner, H. K. Kim, J. A. Abramite, Z. Wang, Z. Guo, Y. Lu, J. Am. Chem. Soc. 2004, 126, 10812 .

[25] K. Okrasa, R. J. Kazlauskas, Chem. Eur. J. 2006, 12,1587

[26] A.Fernandez-Gacio, A. Codina, J. Fastrez, O. Riant, P. Soumillon, ChemBioChem 2006, 7, 1013.

[27] T. Kokubo, T. Sugimoto, T. Uchida, S. Tanimoto, M. Okano, J. Chem. Soc., Chem. Commun. 1983, 769.

[28] M. T. Reetz, N. Jiao, Angew. Chem., Int. Ed. 2006, 45, 2416

[29] A. J. Boersma, J. E. Klijn, B. L. Feringa, G. Roelfes, J. Am. Chem. Soc. 2008, 130, 11783.

[30] R. S. Roy, B. Imperiali, Prot. Engineering 1997, 10, 691

[31] D. Coquière, B. L. Feringa, G. Roelfes, Angew. Chem., Int. Ed. 2008, 46, 9308

[32] N. Shibata, H. Yasui, S. Nakamura, T. Toru, Synlett 2007, 1153.

[33] 'Methods in Enzymology', Vol. 184, Eds. M. Wilchek, E. A. Bayer, Academic Press, San Diego, 1990.

[34] A. Loosli, U. E. Rusbandi, J. Gradinaru, K. Bernauer, C. W. Schläpfer, M. Meyer, S. Mazurek, M. Novic, T. R. Ward, Inorg. Chem. 2006, 45, 660.

[35] 'Methods in Molecular Biology', Vol. 418, Ed. R. J. McMahon, Humana Press, Totowa, 2008

[36] M. Creus, T. R. Ward, Org. Biomol. Chem. 2007, 5, 1835

[37] N. Humbert, A. Zocchi, T. R. Ward, Electrophoresis 2005, 26, 47.

[38] A. Zocchi, A. M. Jobé, J.-M. Neuhaus, T. R. Ward, Prot. Expr. Purif. 2003, 32, 167.

[39] C. Letondor, A. Pordea, N. Humbert, A Ivanova, S. Mazurek, M. Novic, T. R. Ward, J. Am. Chem. Soc. 2006, 128, 8320.

[40] S. Mazurek, T. R. Ward, M. Novic, Mol. Divers. 2007, 11, 141.

[41] G. Klein, N. Humbert, J. Gradinaru, A Ivanova, F. Gilardoni, U. E. Rusbandi, T. R. Ward, Angew. Chem., Int. Ed. 2005, 44, 7764

[42] U. E. Rusbandi, C. Lo, M. Skander, A Ivanova, M. Creus, N. Humbert, T. R.
Ward, Adv. Synth. Catal. 2007, 349, 1923

[43] J. Collot, N. Humbert, M. Skander, G. Klein, T. R. Ward, J. Organomet. Chem. 2004, 689, 4868

[44] T. R. Ward, Chem. Eur. J. 2005, 11, 3798.

[45] M. Skander, C. Malan, A. Ivanova, T. R. Ward, Chem. Commun. 2005, 4815.

[46] 'Topics in Organometallic Synthesis', Vol. 14, Ed. J. Tsuji, Springer, Berlin, 2005.

[47] B. M. Trost, M. L. Crawley, Chem. Rev. 2003, 103, 2921

[48] C. Lo, unpublished result.

[49] K.-J. Haack, S. Hashiguchi, A. Fujii, T. Ikariya, R. Noyori, Angew. Chem., Int. Ed. Engl. 1997, 36, 285.

[50] S. Hashiguchi, A. Fujii, K.-J. Haack, K. Matsumura, T. Ikariya, R. Noyori, Angew. Chem., Int. Ed. Engl. 1997, 36, 288

[51] M. Creus, A. Pordea, T. Rossel, A. Sardo, C. Letondor, A. Ivanova, I. LeTrong, R. E. Stenkamp, T. R. Ward, Angew. Chem., Int. Ed. 2008, 47, 1400.

[52] A. Pordea, T. R. Ward, Chem. Commun. 2008, 4239.

[53] M. Yamakawa, I. Yamada, R. Noyori, Angew. Chem., Int. Ed. 2001, 40, 2818.

[54] A.Schlatter, M.K.Kundu, W.-D.Woggon, Angew. Chem., Int. Ed. 2004, 43, 6731.

[55] A. Schlatter, W.-D. Woggon, Adv. Synth. Catal. 2008, 350, 995.

[56] C. M. Thomas, C. Letondor, N. Humbert, T. R. Ward, J. Organomet. Chem. 2005, 690,4488 .

[57] K. A. Jorgensen, Chem. Rev. 1989, 89, 431.

[58] J. DeChancie, K. N. Houk, J. Am Chem. Soc. 2007, 129, 5419.

[59] Y. Eisenberg-Domovich, Y. Pazy, O. Nir, B. Raboy, E. A. Bayer, M. Wilchek, O. Livnah, Proc. Natl. Acad. Sci. U. S. A. 2004, 101, 5916. 